Revista do Departamento de Geografia
Universidade de São Paulo
www.revistas.usp.br/rdg
ISSN 2236-2878

\title{
A PERCEPÇÃO DO ESPAÇO E O ESPAÇO DA PERCEPÇÃO: O RITMO, O HABITUAL, A INCERTEZA E O EXTREMO NO ENTENDIMENTO DAS SITUAÇÕES ATMOSFÉRICAS DO COTIDIANO E DO NÃO COTIDIANO
}

\author{
THE PERCEPTION OF SPACE AND THE SPACE OF PERCEPTION: \\ THE RHYTHM, THE HABITUAL CONDITION, THE UNCERTAINTY AND THE EXTREME \\ IN THE UNDERSTANDING OF THE EVERY DAY AND \\ THE UNUSUAL CONDITIONS OF THE ATMOSPHERE
}

\author{
Lucí Hidalgo Nunes \\ Universidade Estadual de Campinas \\ luci@ige.unicamp.br
}

\begin{abstract}
Resumo: Procurei aqui discorrer teoricamente, mas com exemplos, a respeito de alguns componentes muito presentes na produção acadêmica de Monteiro voltada para a climatologia, e como elas influenciam o entendimento geográfico do clima no Brasil. Entre esses elementos estão as noções de habitual (em contraponto com "normal"), extremo, incerteza, dinâmica, articulação de escalas e degradação ambiental, mostrando que essas questões e a discussão desse autor, continuam sendo contemporâneas. Ênfase foi dada para a noção de ritmo e para a importância do nível regional nos estudos do clima em particular, e da geografia em geral.
\end{abstract}

Palavras-chave: Monteiro, Ritmo, Regional, Habitual, Extremo.

\begin{abstract}
I tried to discuss theoretically, but with some examples, some components which are found in Monteiro's academic contributions on Climatology and how they influence the understanding of climate under the geographical perspective in Brazil. Among these elements are the idea of habitual condition (instead of "normal"), extreme, uncertainty, dynamics, articulation of scales and environmental degradation, showing that these issues and Monteiro's approaches for these aspects are still very contemporary. Emphasis was given to the notion of rhythm and to the importance of the regional scale in climatic studies and in geography.
\end{abstract}

Keywords: Monteiro, Rhythm, Regional, Habitual Condition, Extreme. 


\section{ALGUMAS QUESTÕES RECORRENTES NA OBRA DE MONTEIRO}

A que pese todo o conhecimento e tecnologia acumulados pela sociedade humana, somos ainda - e talvez sejamos sempre - extremamente dependentes das situações habituais do ritmo climático. Tais condições não somente direcionam nossas escolhas pessoais e mais óbvias, como vestuário e alimentação, mas impigem padrões à produção agrícola, à produção e ao consumo de energia, além de influenciar a saúde e se relacionar à integridade física das pessoas.

Contudo, conforme expressa Monteiro (1971, 1973), o ritmo climático não é composto somente de situações habituais ou mais comuns: qualquer clima registra, de tempos em tempos, eventos extremos, que em uma definição simples são ocorrências que se distanciam das condições mais usuais sendo, por definição, menos frequentes. Antes de discorrer sobre os eventos extremos, é preciso salientar que mesmo o habitual não é um estado único, conforme ressalta Tribbia (2002). Tendo por exemplo o fenômeno ENOS ${ }^{1}$, esse autor lembra (e isso é válido para outros processos) que o estado "normal" (aspas do autor) apresenta variabilidades, sendo que o que se constitui em uma condição "normal" para a população tem por base não a ciência, mas a percepção compartilhada pelos indivíduos, por setores da economia e pela sociedade em geral.

De qualquer forma, eventos de qualquer natureza apresentam ocorrências extremas que, por definição, são mais raras. Mas elas acontecem em algum momento, de modo que o elemento surpresa é saber quando será registrado o próximo episódio, porque (e isso é certo) mais cedo ou mais tarde ele acontecerá. E como virtualmente todas as atividades humanas são reguladas pelas condições habituais do clima, qualquer irregularidade momentânea nesse padrão (como um evento extremo) pode acarretar desarranjos de todas as ordens, que podem afetar muito além do local onde a eventual disritmia tenha ocorrido. Exemplos para ilustrar esse fato não faltam, mas somente para citar um caso recente: os baixos volumes de chuva registrados em setores do sudeste brasileiro entre 2014 e 2015 causaram quase comoção na região e em todo o país, tendo em vista o grande peso da economia dos estados mais afetados, entre eles, São Paulo. Expressões como "colapso iminente", "crise hídrica" abundaram na mídia e nas conversas do dia a dia, e medidas governamentais irresponsáveis - que, na verdade, se traduziram na quase ausência de medidas sérias e eficazes que o momento urgia - somente não culminaram em um grande desastre porque o período de seca mais severa foi encerrado a partir do verão de 2016. Disso se conclui muitas coisas, entre as quais que quanto maior a importância econômica e a densidade populacional de um local, maior é a sua dependência de condições habituais da atmosfera, que nessa lógica deveriam evoluir sem surpresas e sem eventos extremos. Porém, isso é uma impossibilidade física, já que elas fazem parte do clima.

Esses fatos atestam que o ápice do conhecimento acumulado pela humanidade não apenas não nos liberta das condições naturais, mas, paradoxalmente, nos tornam mais dependentes delas - ou, pelo menos, do ritmo habitual - o que se confronta com um dos ideais da modernidade: a crença de que a humanidade poderia dominar tecnicamente a natureza e a sociedade e, portanto, ter maior controle sobre os acontecimentos (CHAUÍ, 2001). Quanto a isso, ainda que a previsão de fatos naturais, como os de natureza atmosférica, possibilitaria, em princípio, antecipar-se a eles e, a partir de seu conhecimento, dominá-los, diante da célere transformação ambiental essa possibilidade, caso se concretize algum dia, está longe de ser realidade.

Isso nos remete às incertezas, e nada mais certo do que o incerto! Não sabemos qual será o resultado de um campeonato esportivo, como será o inverno daqui a três anos no hemisfério Sul (nem no hemisfério Norte), quando acontecerá um forte terremoto, uma nova crise econômica global, ou mesmo, em tempos tão sombrios, quando e onde poderá ocorrer novo atentado terrorista.

Entre as dificuldades envolvidas na conceituação da incerteza está o fato de que ela assume diferentes significados de acordo com o campo científico (CHAUBEY et al.,1999; SAMSON et al., 2009). Ademais, Paté-Cornell (1996) lembra que definir e mensurar a incerteza é tarefa particularmente crítica quando envolve acontecimentos que podem causar grandes impactos, como é o caso dos fenômenos do tempo e do clima.

\footnotetext{
${ }^{1}$ Cuja fase fria ou negativa, mais conhecida por El Niño, foi discutida por Monteiro em 1999. Revista do Departamento de Geografia, Volume Especial (2016) 1-8
} 
A ciência procura tratar a incerteza como uma imprecisão passível de ser quantificável, mas a predição do incerto é exercício difícil e ingrato, pois o erro inerente de uma dada previsão, mesmo que baixo, conduz ao descrédito e aumenta os riscos dos eventos futuros. E a tudo isso se soma o fato de que as grandes e sensíveis mudanças do mundo contemporâneo têm contribuído para aumentar as incertezas de todas as ordens.

Tomando por exemplo o sistema climático (embora a ideia se aplique a qualquer outro sistema), aquilo que é comum, habitual, rotineiro, apresenta grau de incerteza de acontecimento baixo sendo, portanto, considerado um "evento normal" (aspas minhas). Nessa lógica, as ocorrências mais incomuns, inconstantes, infrequentes e que, portanto, teriam maior grau de incerteza de seu registro seriam "anormais" (aspas minhas). Por essa perspectiva, considerar o habitual como normal é ter o extremo como aberração, uma anormalidade que conduziria à catástrofe, que decorreria do descontrole ou da ineficácia em acabar com a incerteza. Com isso, o desastre seria inerente dessa anormalidade, dessa incerteza e, por isso, fatalista.

Se contemporaneamente alcançamos o máximo do conhecimento, a convivência salutar dos seres humanos no seu ambiente, independente de qual seja, parece cada vez mais distante, haja vista o avançado estágio de degradação ambiental em todos os biomas - mais uma vez, para me restringir a um exemplo óbvio. Isso evidencia, entre tantas coisas, que a ciência não está configurada para responder aos grandes problemas atuais; pelo contrário, ela é um elemento de criação de novos problemas, sem que os antigos tenham sido superados.

Vivemos, assim, em um momento perigoso e em um mundo ameaçador e repleto de incertezas, antigas e novas. Antigas porque não conseguimos responder aquelas que perseguem a humanidade desde sempre, como os rumos da vida e a morte, que no dizer popular, é a certeza na incerteza. Novas, porque a dinâmica dos seres humanos opera em ritmo muito mais acelerado do que a dos outros processos do planeta, e muitos são os indicadores dessa outra disritmia: a perda da biodiversidade, com extinções que se processam em taxas muitas vezes maiores do que outrora, com destaque para o desmatamento selvagem, que só é mais célere nos trópicos hoje porque as florestas temperadas já foram devastadas há mais tempo; o desaparecimento de importantes cursos d'água sejam rios, lagos ou mares interiores ${ }^{2}$, ou a urbanização intensa, que altera o balanço de energia local, promove todas as formas de poluição e confere papel secundário às funções ecológicas dos centros urbanos.

Hoje, a maior parte das pessoas vive nas cidades, confinadas por horas a fio em ambientes artificializados, incapazes de notar as mudanças de tempo atmosférico com o passar das horas, demonstrando distanciamento das condições físicas. O não reconhecimento da evolução das condições do tempo arroga mais valor ao conhecimento obtido de forma rápida por diferentes mídias, tão facilmente acessáveis e acessíveis, do que a própria vivência pessoal, construindo um mundo erigido e comandado por artificialidades, onde o externo sobrepuja o interno, onde a vida se desconecta do lugar de vivência. Conforme argumenta Porto-Gonçalves (2006), isso revela crescente perda da identidade com o lugar, inibindo e até destruindo sinergias e interações.

Os conhecimentos empíricos passados por gerações através de dizeres, músicas e observações se perdem em um mundo que não apenas não os valorizam, mas que muda em grande velocidade: poluição, ilha de calor e flora e fauna exógenas são novos elementos desse novo ambiente, e essa transformação torna seu ritmo de difícil reconhecimento. A percepção do ambiente não é construída, pois os espaços confinados ${ }^{3}$ não propiciam a observação do meio físico (e até construído). O não desenvolvimento da percepção do ambiente faz com que padrões de variabilidade inerentes ao regime climático não sejam mais reconhecidos pela população local, constituindo-se em combustível para os exageros relacionados aos temores das eventuais mudanças climáticas: qualquer precipitação é excepcional, qualquer ocorrência é um desastre, qualquer fato local se interliga ao aquecimento global. Tais informações distorcidas, veiculadas com frequência pela mídia sem explicações e, por vezes, acompanhadas por imagens dramáticas (nem sempre do local e do evento da

\footnotetext{
${ }^{2} \mathrm{O}$ desaparecimento do Mar de Aral é apontado por alguns como a maior tragédia ecológica promovida pelo ser humano, mas não ficam atrás a diminuição do lago Chade e de áreas do Crescente Fértil.

${ }^{3}$ Janelas fechadas, plantas artificiais, edificações tão altas e próximas entre si que dificultam ou até impedem a observação do horizonte.
} 
notícia) são tidas como críveis e, pior: geram temor e até aversão da população aos fatos do ambiente. Se tantas informações por um lado contribuem para que a questão climática se torne cada vez mais presente no imaginário coletivo, o distanciamento dos fatos atmosféricos reais é cada vez maior, ainda que eles tenham papel central na percepção do ser humano sobre as potencialidades e fontes de risco do território. Com isso, ocorre verdadeira "demonização" das condições do ambiente físico (as árvores, as chuvas, os rios, o ar, tudo que é natural é ruim), aspecto que Nunes e Zamparoni (2014) discutem em trabalho sobre a disseminação de informações climáticas pela mídia escrita, que certamente influencia a percepção individual do ambiente.

Por outro lado, é igualmente verdadeira e atual a colocação de Foladori (2001) de que aos problemas em escala local ou regional (poluição do ar das cidades, rios contaminados, detritos sólidos amontoados), somam-se aqueles de escala planetária (aquecimento global, redução da camada de ozônio, perda da biodiversidade). E tanto a dissociação com as condições locais e cotidianas como a desestruturação em escala regional e planetária se associam diretamente à produção do risco, que é uma construção social, multifatorial, multiescalar e dinâmica (NUNES, 2015).

\section{O CARÁTER ATEMPORAL DA OBRA DE MONTEIRO, OU COMO A CIÊNCIA REDESCOBRE O QUE ELE JÁ SABIA}

Todas essas questões tão contemporâneas como ritmo, extremos, dinâmica, incertezas, articulação de escalas e degradação ambiental são presentes e soberbamente desenvolvidas na Obra de Monteiro, no qual cada produção de sua longa e profícua jornada reforça os fatos previamente avaliados e põe em cena novos argumentos, que contribuem para o avanço teórico não apenas dos fatos atmosféricos, mas da geografia ${ }^{4}$. Aliás, um grande trunfo dos estudos de Monteiro é que mesmo (aparentemente) tendo por objetivo a avaliação das condições atmosféricas de um determinado local, eles jamais se limitaram à mera discussão das características dos setores avaliados; pelo contrário, as análises serviram como estudos de casos para desenvolvimentos teóricos que se constituíram, assim, em base sólida para investigações semelhantes para outros locais, mesmo que caracterizados por ritmos climáticos bastante diferenciados - fato que sublinha 0 caráter essencialmente nomotético de sua produção. Assim, de seus exemplos ficaram, acima de tudo, a teoria, mas também o conhecimento das condições atmosféricas dos setores brindados por suas investigações.

Em sua Obra superlativa e sempre contemporânea, alguns elementos merecem destaque, não apenas pela importância que eles têm na construção de sua linha teórica, mas pela influência na produção da climatologia brasileira: irei me deter, contudo, em dois deles, pois eles me parecem centrais em sua Obra e porque noto a retomada desses assuntos na ciência: são eles o papel central da escala regional e o ritmo nos fenômenos naturais.

\section{A escala regional na escola de Monteiro}

Escala é assunto recorrente para Monteiro, que conferiu a devida importância para todos os níveis no estudo dos fenômenos atmosféricos. Porém, um deles é proeminente nas suas discussões: mesmo com o destaque para a escala local na sua grande marca, a análise rítmica (MONTEIRO, 1971), nível que diversifica e especializa a realidade climática, e também para o nível zonal (ou topo), que controla o recebimento de energia e a partir do qual ocorrem as diferenciações climáticas, é o nível regional (ou meso) que o autor elege como essencial, ao organizar e conferir unicidade (MONTEIRO 1976; 1999).

Descrita como aquela que possibilita a compreensão dos fatos geográficos por excelência, a escala regional é destaque em toda a Obra de Monteiro, pois se o nível zonal confere as características mais gerais do clima, que se mantêm nos níveis hierárquicos abaixo dele, e é na escala local que qualquer fato geográfico se materializa, na mesoescala ocorrem as articulações e emanam os verdadeiros controles do ritmo da atmosfera.

\footnotetext{
${ }^{4}$ E como parto do princípio que tudo é geográfico (já que muitos colocam que tudo é político), subentenda-se que mesmo em sua Produção não científica esse fato é presente.
} 
A importância do nível regional, sempre presente nas preocupações de Monteiro, é um exemplo do quão a frente de seu tempo ele sempre esteve, tendo em vista o recente protagonismo dessa escala para alguns pesquisadores da área ambiental. Messerli et al. (2000) discutem a relevância da perspectiva regional na avaliação de fenômenos que operam em sistemas dominados por processos antropogênicos, os quais, como lembram Turner et al. (1990) dominam os impactos cumulativos, como perda de habitats e de biodiversidade, diversas formas de poluição e erosão. Por sua vez, o geógrafo britânico Dearing et al. (2006) ressaltam que a instância regional é central para a compreensão das interações dinâmicas entre seres humanos e o meio físico e das mudanças ambientais operantes em todas as escalas, sendo também o nível da formulação de estratégias científicas e políticas de mitigação e adaptação.

Em seu excelente estudo que teve por pano de fundo o entendimento da distribuição das chuvas no estado de São Paulo, mas que reforça, com esse exemplo, que o clima só pode ser entendido pelo ritmo conferido pela sucessão dos tipos de tempo, Monteiro (1973) enfatiza o protagonismo do nível regional. Com maestria ele demonstra que as diferenças no volume e na distribuição temporal e espacial da chuva são fruto da circulação regional, que para São Paulo tem por comando o sistema extratropical, visto que anos com maior atuação de massas polares registram totais mais elevados de chuva e vice-versa, mesmo com os sistemas tropicais ${ }^{5}$ atuando na maior parte dos dias do ano. A tipologia climática de base dinâmica que aparece no final desse trabalho é estabelecida de acordo com o domínio dos sistemas atmosféricos, cujas alternâncias são ditadas pelos centros de ação, que agem regionalmente.

Para dar outro exemplo da importância da escala regional, podemos lembrar um assunto que também está presente nas preocupações do Autor: a poluição atmosférica, que em sua Obra Teoria e Clima Urbano $(1976)^{6}$ constitui-se no subsistema físico-químico (Canal de Percepção II). Para mostrar a importância dos controles regionais do clima na poluição, exemplifiquemos com casos internacionais, começando pela Polônia: para isso, consideremos tanto o período anterior à queda do muro de Berlim, como após esse evento histórico. O principal recurso energético desse país é o carvão, que mesmo de melhor qualidade do que o nacional é bastante poluente. Todavia, imediatamente após a queda do Muro de Berlim, no começo dos anos 1990, a Polônia e outras nações da ex-Cortina de Ferro rapidamente passaram a integrar o mercado econômico globalizado, o que levou a um maior uso de energia, fato acompanhado de níveis de poluição muito altos, tendo em vista a base energética polonesa. O preço pago foi elevado: a saúde da população, já que o controle regional do clima é dominado por sistemas de alta pressão, desfavoráveis para a dispersão dos poluentes.

Não faltam exemplos de situações desfavoráveis à dispersão da poluição, condicionados pelos arranjos dos centros de ação, que operam no nível regional: pouco antes do início das Olimpíadas de 2008 a cidade de Beijing, China, foi (mais uma vez) dominada por persistente poluição, o que causou grande preocupação, já que o desempenho esportivo pode ser comprometido em situações de índices muito altos de poluição atmosférica. Em março de 2014 uma sequência de noites frias e de dias quentes em Paris (situação atmosférica típica de alta pressão, sem presença de nuvens e, consequentemente, com forte gradiente térmico diuturno) levaram a cidade a registrar níveis alarmantes de poluição do ar, transformando-a de Cidade Luz em Cidade do Smog, como foi momentaneamente apelidada pela imprensa internacional. A situação atmosférica forçou medidas de emergência que restringiram por alguns dias a circulação de veículos na capital francesa. Outros "clássicos da poluição mundial" também aconteceram em situação de domínio persistente de alta pressão, desfavorável à dispersão da poluição: Vale de Meuse, Bélgica, em dezembro de 1930, quando grossa camada de poluição por cinco dias provocou 63 mortos e doenças em 6.000 pessoas; Donora, Estados Unidos, em outubro de 1948, com 20 mortos e problemas respiratórios que atingiram quase metade da população (7.000 pessoas) e Londres, em dezembro de 1952, quando cinco dias com condições anticiclonais provocaram 4.000 mortes (LUTGENS E TARBUCK, 2007).

Não obstante, o predomínio de baixas pressões pode contribuir para disseminar os poluentes por grandes áreas: talvez o caso mais dramático seja o acidente nuclear em Chernobyl, Ucrânia (na ocasião, parte da União Soviética) em 26 de abril de 1986: devido as condições atmosféricas, a pluma de poluição rapidamente atingiu outros países, como Polônia (no dia seguinte), Suécia (28 de abril) e entre 29 e 30 de abril ela se espalhou por países da Europa Central. A alta temperatura também contribuiu para esses compostos atingissem altitudes consideráveis (EUROPEAN NUCLEAR SOCIETY).

\footnotetext{
${ }^{5}$ Com predomínio do atlântico nos setores mais orientais, e participação crescente do continental, mais a oeste, e eventuais invasões do sistema equatorial em setores mais setentrionais.

${ }^{6}$ Constante fonte de inspiração, não interessa quantas vezes seja relido.
} 
Partindo para uma leitura geográfica não calcada nos atributos da atmosfera, nota-se que nos últimos anos o mundo se configura em um padrão no qual os blocos econômicos regionais ${ }^{7}$ ganham destaque (alguns bem mais do que outros), rearranjando a estrutura territorial do poder, pois o peso de alguns blocos tende a superar o poder nacional ${ }^{8}$, tornando o conjunto dos países envolvidos mais competitivo na esfera globalizada. No plano nacional esse modelo é representado pelas regiões metropolitanas, que representariam nodos de desenvolvimento. Esses arranjos regionais têm reflexos na elaboração de políticas socioeconômicas e territoriais de interesse comum, sendo que algumas são diretamente relacionadas ao clima: é o caso de metas regionais para diminuição da emissão de gases de efeito estufa, que independente do eventual impacto positivo no aquecimento planetário de caráter antropogênico, diminuiria os níveis de poluição.

\section{O ritmo na Obra do maestro Monteiro}

A ideia do ritmo, que capitaneia a Produção de Monteiro e, a partir dele, tantas outras contribuições na geografia (talvez incompreendida por alguns), aparece também em autores criativos e visionários: um deles é o oceanógrafo sul africano radicado nos Estados Unidos por muito tempo, George Philander, autor que em 1989 revolucionou a compreensão do principal fenômeno de teleconexão que afeta os trópicos: o ENOS (El Niño Oscilação Sul). Em muitos aspectos acho que esses pesquisadores têm muitas afinidades, embora provavelmente jamais tenham se encontrado: ambos têm dado contribuição maiúscula e inestimável para a compreensão de mecanismos atuantes nos dois principais meios fluidos do planeta (atmosfera e oceano) e suas contribuições os destacam de seus pares, já que elas são sempre um marco na ciência. Além disso, a didática também acompanha os dois, pois é fácil entender os ensinamentos desses mestres, mesmo tratando eles de fenômenos complexos e de forma revolucionária, e cada nova leitura de um velho texto revela algo que escapou anteriormente (como conseguem dar a eterna sensação de novidade?). Contudo, o que eu mais gosto nos dois é a forma sensível, harmoniosa, entusiasmada e poética de descrever os fenômenos físicos: chegamos a esquecer que estamos lendo teoria científica, enlevados que somos pela cadência da escrita e pelos exemplos cativantes, que torna a consulta muito prazerosa.

Também Philander sentiu, com sensibilidade, os acordes da natureza, o ritmo dos processos físicos, ao descrever em sua obra de 1998 os fenômenos do tempo atmosférico (weather) como a música da nossa esfera, no qual a sucessão se dá de forma cadenciada, rítmica: atentar que esse autor também usa o termo ritmo (rhythm) como componente do tempo atmosférico.

Quem se interessa verdadeiramente pela ciência não deve, nem mesmo pode, ser linear e cartesiano, achando que a o ritmo é algo que se manifesta de uma única forma, que seria agradável e aprazível a todos os gostos e captável de uma única maneira. Ora, o ritmo da musicalidade oriental não é tão tragável para os ouvidos ocidentais, e vice-versa! E por que deveria ser? E o que seria do conhecimento se não fossemos capazes de estabelecer paralelos, de fazermos comparações, enfim, se a ciência fosse essencialmente idiográfica? Não resta dúvida que há uma singularidade na manifestação dos fenômenos, de sorte que quando consideramos um regime climático, qualquer que seja, cada ano é, em alguma extensão, diferente do precedente e será distinto do seguinte. Mas em um conjunto maior é possível detectar padrões comuns, similares, que distingue esse de outros tipos climáticos, ou possibilita observar mudanças nesse regime a partir de padrões que se distanciam muito daquele antigamente observado. $\mathrm{O}$ ritmo do clima não é o ritmo da música que encanta nossos ouvidos (até porque enquanto alguns preferem o samba, outros escutam o tango, o rock, o sertanejo...). Os acordes e as cadências são outros, mas se não houvesse uma harmonia rítmica nos processos bióticos e abióticos do planeta, não existiriam arranjos entre todas as esferas da Terra.

Conforme explicam os mestres Philander e Monteiro, os processos do planeta têm ritmo, cuja harmonia se faz presente nas trocas que se processam e que assim possibilitam que o planeta exista como tal. No fundo, essa discussão passa por algo que muito pouco é tratado de forma científica na geografia, mas que está em seu cerne: a diversidade, pois nessa ciência estudamos manifestação das diferenças nos inúmeros componentes do planeta, avaliando suas semelhanças e diferenças no espaço e no tempo - dimensões indissociáveis, como alertou outro grande autor Szamosi (1988) $)^{9}$. A aceitação da diversidade depende da disposição de aceitar o diferente e ter a mente aberta para sentir que ela é fruto dos arranjos dinâmicos das

\footnotetext{
${ }^{7}$ União Europeia, Cooperação Econômica da Ásia e do Pacífico, Mercosul, BRICS, Unasul e Nafta, entre outros.

${ }^{8} \mathrm{O}$ que pode, em alguns casos, causar efeito contrário, ou seja, abandono do bloco quando os países sentem a perda da identidade para essa entidade maior, conforme aconteceu recentemente com o "Brexit".

${ }^{9}$ Como geógrafa sempre me incomodou é o fato de que alguns colegas relegam a um segundo plano a dimensão temporal (ou até a ignoram) como se os arranjos espaciais fossem eternos.
} 
variáveis, ditados por cadências compassadas. Há ritmo em tudo: na formação do solo, no desenvolver das plantas, na gênese das precipitações... Porque não haveria no clima? Ritmo é termo científico corrente em várias disciplinas. Mas não basta seu uso indiscriminado: a propriedade de sua utilização se faz pelo desenvolvimento teórico, que é o que Monteiro fez para o entendimento do ritmo no clima.

\section{Monteiro, o visionário}

Por fim, resta-me sublinhar primeiramente que a marca de Monteiro é presente na ideia que revolucionou a compreensão do clima, que é alcançar sua compreensão partindo de unidades menores (tempo atmosférico), que em sequência cadenciada pelos diferentes ritmos conduzem à compreensão da dimensão maior, que é o clima. Talvez não seja exagero classificar essa valorização das pequenas unidades como um grande avanço, visto que um dos traços da ciência hoje é a aquilatar os pequenos elementos: por exemplo, o grande interesse da moderna ciência física é a nanotecnologia.

Também não posso deixar de mencionar que o grande laboratório de Monteiro tem sido o meio urbano (MONTEIRO, 1976; MENDONÇA E MONTEIRO, 2003), que tem por característica maior sua capacidade de modificar, de forma contumaz, o meio físico e as relações dos seres humanos com seu substrato, ao acelerar (e cada vez mais homogeneizar) os fluxos sociais, culturais, políticos e econômicos. Quanto a isso, em 1961 Mumford já arguia quanto à desmaterialização das relações e das instituições da cidade por meio de redes físicas ou culturais distributivas. Nas palavras de outro grande teórico da ciência geográfica brasileira, contemporâneo de Monteiro e que igualmente se dedicou ao estudo do clima (mas não somente), Conti (1997) lembra que a cidade é a grande expressão geográfica do século XX, que sem dúvida podemos prolongar para o século XXI.

Os centros urbanos são espaços da contradição por excelência, pois a cidade é, ao mesmo tempo, local das oportunidades, da igualdade, do futuro, do sucesso e da ascensão, mas igualmente da degradação, da violência, das diferenças e da opressão. Além do mais, algumas características intrínsecas dos centros urbanos como concentração, mobilidade desigual e crescimento desregrado contribuem para o aumento da vulnerabilidade e das catástrofes naturais, muitas das quais deflagradas por situações atmosféricas (NUNES, 2015). E é na cidade que tudo se conecta: percepção, cotidiano, ritmo, incerteza, extremo, desastres. Se muitos estudos e algumas teorias já foram desenvolvidas para a cidade ${ }^{10}$, ainda mais há a se fazer. Com a inspiração de Monteiro e de seus discípulos, a tarefa se torna mais fácil.

\section{REFERÊNCIAS}

CHAUÍ, M. Convite à Filosofia. São Paulo: Ed. Ática, 2001. 440p.

CHAUBEY, C.I.; HAAN, C.T.; GRUNWALD, S.; SALISBURY, J.M. Uncertainty in the model parameters due to spatial variability of rainfall. Journal of Hydrology. v.20, n.1-2, p.48-61, 1999.

CONTI, J. B. A geografia física e as relações sociedade/natureza no mundo tropical. São Paulo: Humanitas FFLCH/USP, 1997. 30 p.

DEARING, J.A.; BATTARBEE, R.W.; DIKAU, R.; LAROCQUE, I.; OLDFIELD, F. Human-environment interactions: learning from the past. Regional Environmental Change, v.6, p.1-16, 2006.

EUROPEAN NUCLEAR SOCIETY. Disponível https://www.euronuclear.org/info/encyclopedia/chernobyl.htm. Acesso em 21 de julho de 2016.

FOLADORI, G. Limites do desenvolvimento sustentável. Campinas: Ed. da UNICAMP, 2001. 221p.

LUTGENS, F.K.; TARBUK, E.J. The Atmosphere. New Jersey: Prentice Hall. 2007. 520p.

MENDONÇA, F. de A.; MONTEIRO, C.A. de F. Clima Urbano. São Paulo: Contexto, 2003. 192p.

MESSERLI, B.; GROSJEAN. M.; HOFER T.; NUÑES, L.; PFISTER, C. From nature-dominated to humandominated environmental changes. Quaternary Science Reviews, v. 19, p. 459-479, 2000.

MONTEIRO, C.A. de F. Análise rítmica em climatologia - problemas da atualidade climática em São Paulo e achegas para um programa de trabalho. Climatologia, São Paulo, v.1, p.1-21, 1971.

\footnotetext{
${ }^{10}$ Uma delas Teoria e Clima Urbano, que continua sendo leitura essencial quatro décadas após sua edição.
} 
MONTEIRO, C.A. de F. A dinâmica climática e as chuvas no Estado de São Paulo (estudo geográfico sobre a forma de atlas). São Paulo: IGEOG-USP, 1973. 130 p.

MONTEIRO, C.A.F. Teoria e Clima Urbano. Série Teses e Monografias n.25, São Paulo: IGEOG-USP, 1976. 181p.

MONTEIRO, C.A. de F. O estudo geográfico do clima. Cadernos Geográficos, Florianópolis, v.1, n.1, p.772, 1999.

MUMFORD, L. The city in history: its origins, its transformations and its prospects. New York: Harcourt, 1961. 627 p.

NUNES, L.H.; ZAMPARONI, C.A.G.P. A Mídia em Foco: Exemplos de Desinformação Climática. In: Multidimensão e Territórios de Risco. Coimbra: Imprensa da Universidade de Coimbra, v. 1, 2014. p.7780 .

NUNES, L.H. Urbanização e desastres naturais na América do Sul: abrangência América do Sul. São Paulo: Editora Oficina de Textos, 2015. 112p.

PATÉ-CORNELL, M.E. Uncertainties in risk analysis: Six levels of Treatment. Reliability Engineering and System Safety, v.54, p.95-111, 1996.

PHILANDER, S.G.H. EI Niño, La Niña and the Southern Oscillation. San Diego: Academic Press, 1989. $293 p$.

PHILANDER, S.G.H. Is the Temperature Rising? The Uncertain Science of Global Warming. New Jersey: Princeton University Press, 1998. 254p.

SAMSON, S.; RENEKE,J.; WIECEK, M.M. A review of different perspectives on uncertainty and risk and an alternative modeling paradigm. Reliability Engineering and System Safety. v.94, p.558-567, 2009.

SZAMOSI, G. Tempo e Espaço: as Dimensões Gêmeas. Petrópolis: Jorge Zahar Ed., 1988. 434 p.

TRIBBIA, J. What constitutes "normal?". In: GLANTZ, M.H. La Niña and its impacts: Facts and Speculation. Tokyo, New York: United Nations University Press, 2002. p.29-43

TURNER B.L.; KASPERSON, R.E.; MEYER, W.B.; DOW, K.M.; GOLDING D.; KASPERSON, J.X.; MITCHELL, R.C.; RATICK, S.J. Two types of global environmental change. Global Environmental Change v.15, p.1-22, 1990. 